\title{
Study of impact of art performance level of blue laser technology applications and its control
}

\author{
Mohanad Aljanabi ${ }^{1}$, Mahmood H. Enad ${ }^{2}$, Jasim Mohmed Jasim ${ }^{3}$ \\ , Rawaa A. Abdul-Nab ${ }^{4}$, Nadia alanı ${ }^{5}$ \\ 1,3,4Electrical Power Techniques Engineering Department, Technical College/AL- Mausaib, \\ Al-Furat Al-Awsat Technical University Najaf, Iraq
}

${ }^{2}$ Electrical Techniques Department, Technical Institute of Karbala, Al-Furat Al-Awsat Technical University, Iraq ${ }^{5} \mathrm{Al}-\mathrm{Musaib}$ Engineering College, Babylon, Iraq

\section{Article Info}

Article history:

Received Jul 20, 2019

Revised Sep 5, 2019

Accepted Sep 27, 2019

\section{Keywords:}

Art performance level parameters of laser Blue laser technology Control of modern experimental measurements

\begin{abstract}
In this work; we present an enhancement in blue laser diodes with new factors and applications for modern technology such as underwater telecommunications, bio-sensor and bio-medical systems etc. Years of advance meanwhile have much enhanced laser performance, and extremely improved their diversity, making lasers significant parts in scientific research, telecommunications, engineering, bio-medical imaging, materials working, and a swarm of other applications. This article viewing how laser technology has progressed to chance application requirements. The enhanced blue laser building diagrams to get a peak efficiency $\%$ at room temperature with modification. Moreover, we have as well estimated electro-optical performance packing of blue laser diodes been significantly various associated to GaAs laser method and novel developments and performances are required to enhance the optical power from anther laser diodes. Researchers need enhanced approaches to accurately make new the blue laser applications to use control of modern experimental measurements and optical communication.
\end{abstract}

Copyright () 2020 Institute of Advanced Engineering and Science. All rights reserved.

\section{Corresponding Author:}

Mohanad Aljanabi,

Electrical Power Techniques Engineering,

Technical College /AL- Mausaib,

Al-Furat Al-Awsat Technical University,

Najaf, Iraq.

Email: com.mhn@atu.edu.iq

\section{INTRODUCTION}

Blue beams are formed by gas lasers using He-Cad at $441.6 \mathrm{~nm}$, and Argon-ion at 458-488 nm. Semiconductor with blue rays are naturally depending on gallium nitride. Both blue and violet lasers can also be built by means of frequency repetition of IR laser $\lambda$ from DL or DPL [1].

In the early 1990s the Institute of High Pressure Physics of Dr. Sylwester established knowledge to make gallium nitride quartzes with high organizational excellence [2-4]. For example, diode lasers are semiconductor devices, they may as well be divided as semiconductor lasers [5].

\section{METHOD AND RATE EQUATIONS OF THE MODELING BLUE LASER}

A laser diode is formed like a plane-paralleled rectangle where the two faces, semiconductors see, form a Fabry-Pérot resonator. This resonator is the source of the emission moved by distinguishing light emission as shown in Figure 1 [6]. From Figure $2 \& 3$ shows energy level of DH-OS Laser Diode and the circuit of blue laser diode. To get a continua land powerful laser of the junction of semiconductors [7]. 


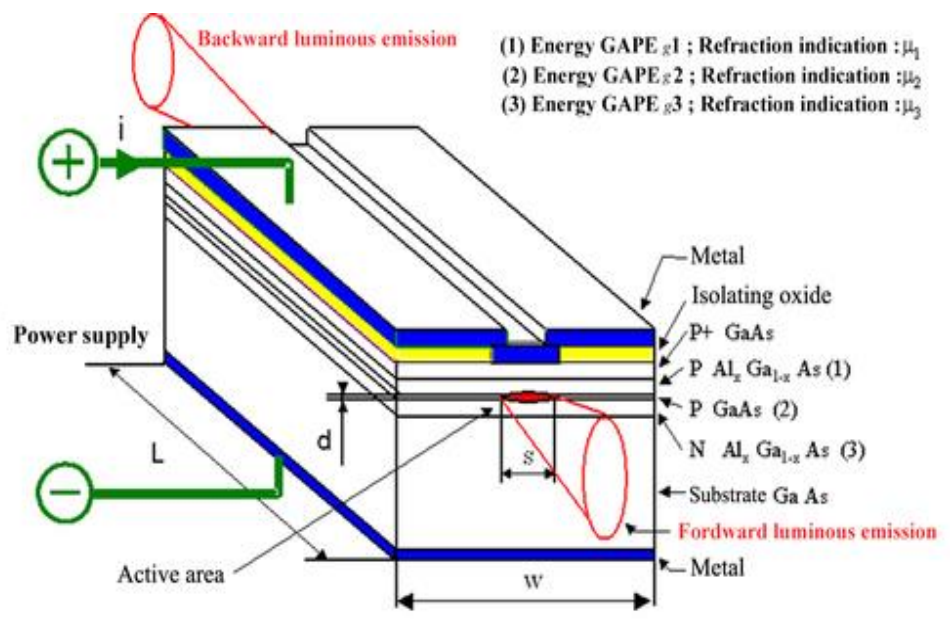

Figure 1. Schematic of DH-OS laser diode

a)

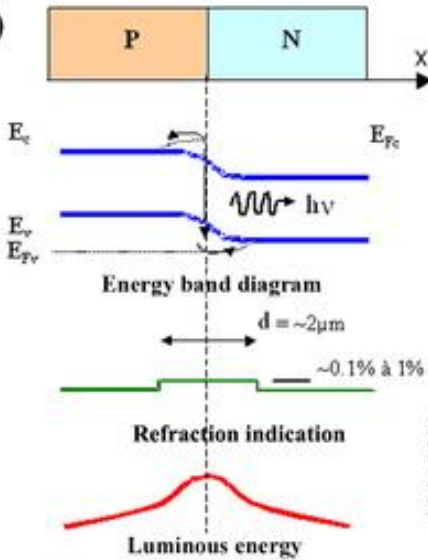

b)

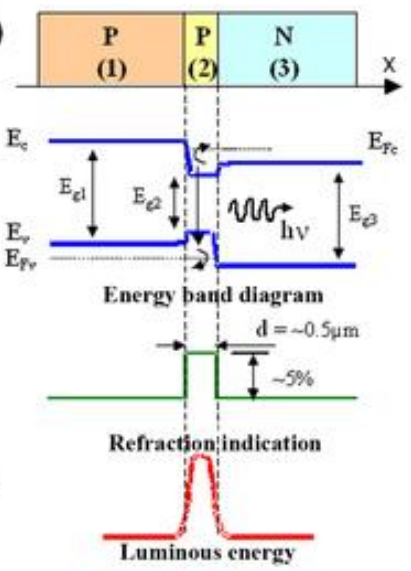

Figure 2. (a) PN-junction of LD, (b) Energy level of DH-OS laser diode [8]

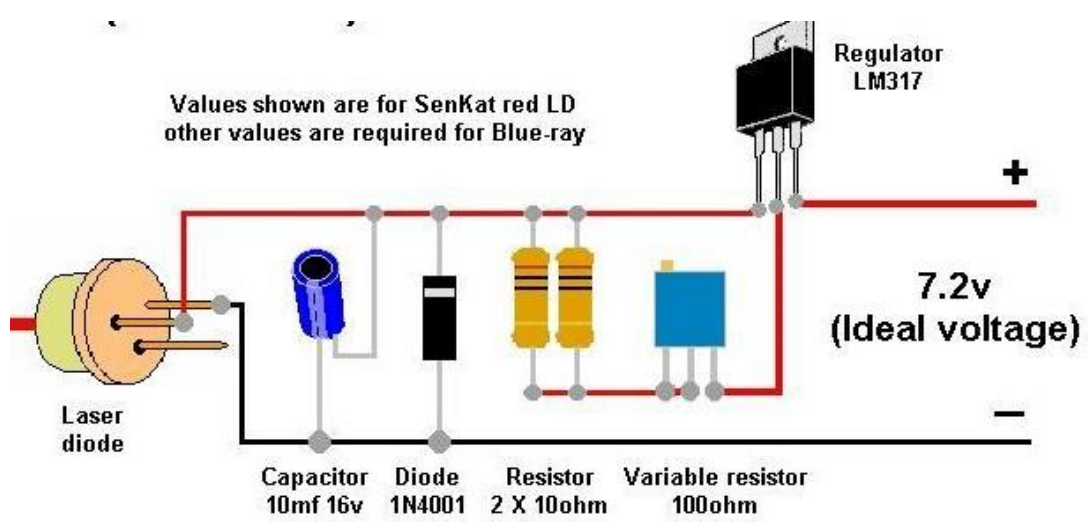

Figure 3. The circuit of blue laser diode [9]

Electrical pumping is usually achieved by means of sufficiently intense electrical discharge. Electrical pumping is well-organized for gases and semiconductors, whose absorption BW is extensive enough. While around optical pumping approaches for semiconductor intermediate have been advanced, electrical pumping for diode lasers demonstrated to be extra suitable [10-13]. 


\section{NUMERICAL SIMULATION (RATE EQUATIONS OF THE MODELING BLUE LASER)}

The energy levels in the conduction band and valence band of Quantum well are strongminded by resolving the 1D time independent Schrödinger equation. It's a measured typical which defines the performance of classification as a function of 3-D and time coordinates in standings of a wave function $(\Psi)$. Solving the Schrödinger to get the probable $\Psi$ that can occur within the section [10].

$$
-\frac{\hbar^{2}}{2 m} \frac{d^{2} \psi(x)}{d^{2} x}+v(x) \psi(x)=E \psi(x)
$$

substituting,

$$
\begin{aligned}
& \psi(\mathrm{x})=A \sin \mathrm{kx}+\mathrm{B} \cos \mathrm{kx} \\
& \frac{\hbar^{2} \mathrm{k}^{2}}{2 \mathrm{~m}}(\mathrm{~A} \sin \mathrm{kx}+\mathrm{B} \cos \mathrm{kx})
\end{aligned}
$$

this gives

$$
E=\frac{\hbar^{2} k^{2}}{2 m}
$$

Outdoor the well, $(\mathrm{x})=0$ and $(\mathrm{x})=\mathrm{A}$ sinkx. Hitting $\mathrm{x}=\mathrm{a}$, wherever (a) is the width of quantum: -

$$
\mathrm{kx}=\mathrm{n} \pi
$$

accordingly, the equivalence develops,

$$
\mathrm{E}=\frac{\hbar^{2} \pi^{2} \mathrm{n}^{2}}{2 \mathrm{ma}^{2}}
$$

this calculation bounces the energy levels for changed values of $n$ can be designed as Figure 4:

The $\Psi$ can be plotted by giving,

$$
\mathrm{A}=\sqrt{\frac{2}{\mathrm{a}}}
$$

which gives the equation

$$
\psi(x)=\sqrt{2 / a} \sin \left(\frac{\pi n x}{a}\right)
$$

Blue laser diodes produce light in the $\lambda$ from 440 to $485 \mathrm{~nm}$. This area of procedure has controlled to submissions in optical information loading and high-determination printing $[14,15]$.

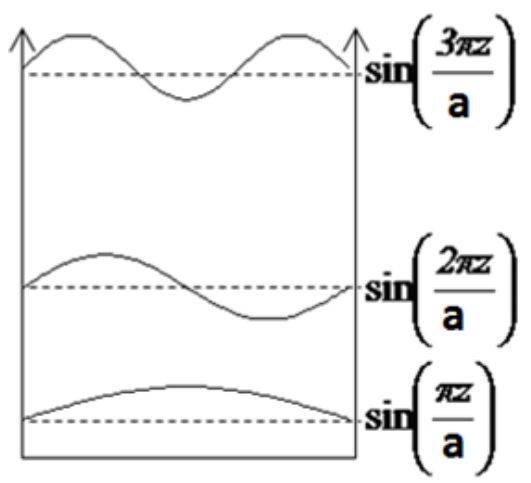

Figure 4. $\Psi$ in quantum well 


\subsection{Materials Used of the Device:}

AIN, GaN, InN materials all have a direct band gap.i.e. the optical transition across the band gab are allowed and therefore much strong than in the case of indirect band gaps as shown in Figure 5, for example of $\mathrm{SiC}[16-19]$.

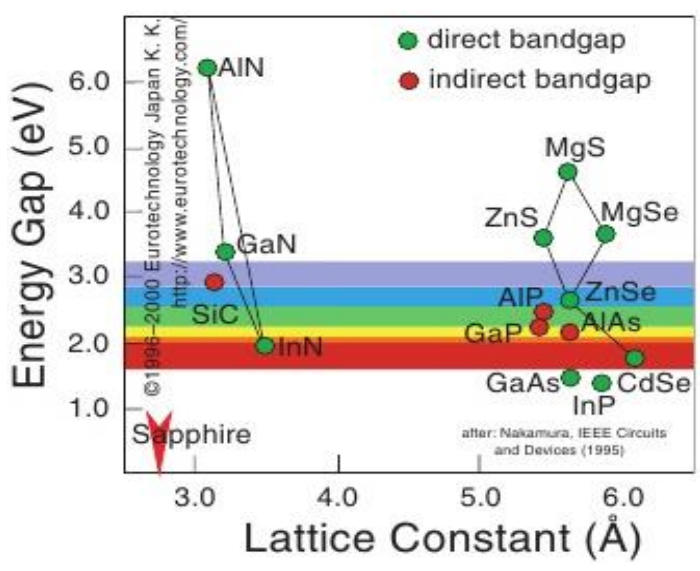

Figure 5. Shows band gap for different materials

Resonant doubling arrangements permit higher efficiencies; $650 \mathrm{~mW}$ in $430 \mathrm{~nm}$ has been confirmed $[20,21]$. Blue or near UV nitride-based semiconductor laser diodes (LDs) are nowadays commercially available. With regard to their short wavelength, lifetime and low power consumption they became suitable for submissions such as fast laser printing, high density optical information storage and, recently, in pico-size projectors occupied with lasers $(400-415) \mathrm{nm}$ with a design centered at 408nm per the laser manufacturers' specification, this strategy was improved with a very large and forgiving clear aperture and is as well rewarded for the laser manufacturers' variation thickness [22]. Schematic structure of Nakamura is shown in Figure 6.

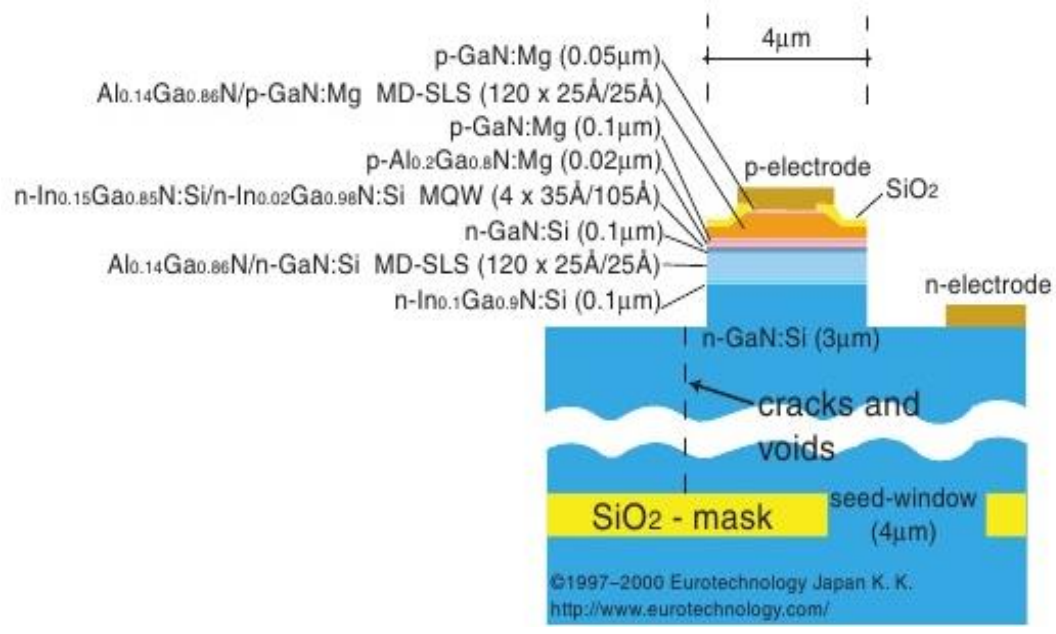

Figure 6. Schematic structure of Nakamura, s blue laser [23]

\subsection{The Device Structure}

The laser diode assembly on a classical substrate as shown in Figure 7, waveguide lasers were invented. Windows associated with the waveguides were imprinted into the $\mathrm{SiO} 2$ to contact the p-electrode. An Au bond pad was disappeared on top of the $\mathrm{SiO} 2$, contacting the p-electrode [24, 25]. 


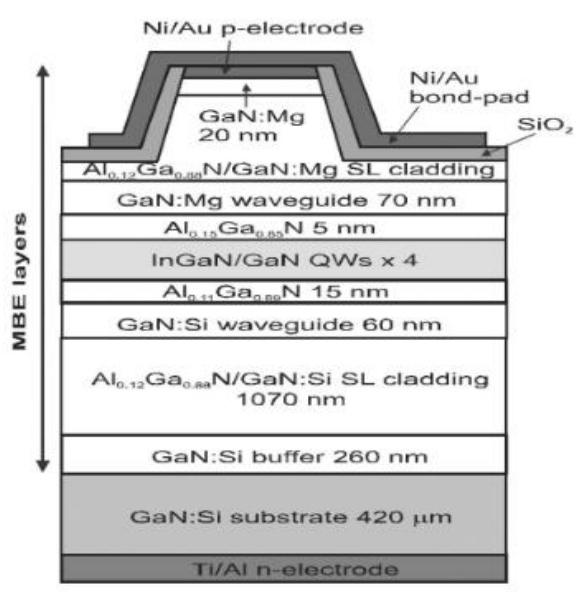

Figure 7. Construction of the InGaN multiple laser diode [26]

\subsection{State of the Art Performance Level of the Device:}

The augmentation takes place in the junction of the semiconductor so only a small part of a small device is involved in the lasing processes. It banquets much less in the plane of the junction than in the plane vertical to the junction. This income that the beam is not $\mathrm{TEM}_{0,0}$, the divergence angles are relatively large, on the order of an insufficient degrees, and the divergence angles are changed in the various planes [27-29]. Holes must be measured in the blue laser courses as well as electrons. The active method to variety an optical cavity for producing F.B is to usage reflected surfaces of planes slashed on the crystal [30]. Figure 8. Display the absorption of the key blue laser performance.

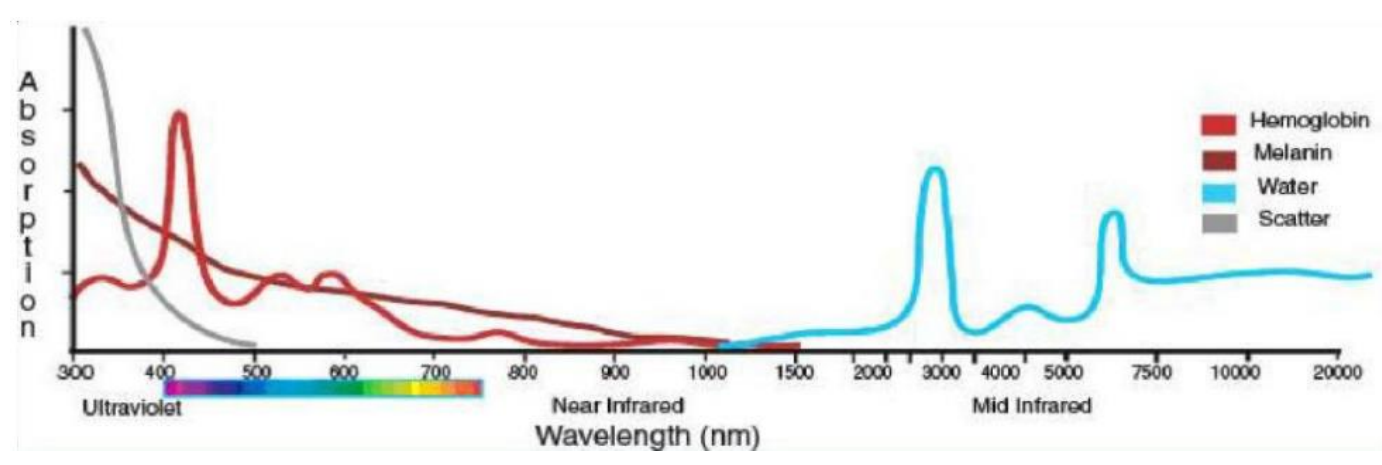

Figure 8. Absorption of the main blue laser performance [30]

\subsection{The Factor that Limit Performance}

The blue laser diode is a relatively recent innovation and did not enter commercial use until 2001. This was due to the difficulty of producing a suitable gain medium and the advances in materials science needed before the technology could become viable. It was primarily the product of research carried out in Poland and Japan, although the blue laser work confirmed the technical problems: -

1. Nonexistence of an appropriate substrate.

2. the disappointment of p-type doping

Scientists at Nichia determined the problematic of the discontinuity in lattice structure at the border molded. Future they enhanced upon the technique by using a buffer layer which is designed by deposit of $\mathrm{GaN}$. The incapacitating was mixed, from $\mathrm{Zn}$ to $\mathrm{Mg}$. The secondary blue laser diodes are twenty hundred periods brighter than the former forms [30].

\subsection{Low Noise}

Low noise outcomes from the cavity construction which restricts the number of oscillation methods and maintains exact control of the component temperature. Only high-quality optical mechanisms are used, resulting in a noise specification of $<5.0 \%$ rms over a wide operating temperature range [31-34]. 
A public portion of the amplitude noise is the comparative intensity noise [35]:

$$
R I N=\frac{\left\langle\Delta P^{2}\right\rangle}{\left\langle P^{2}\right\rangle \approx\left[2 \times \Delta f S_{P}(f)\right]^{2} /\left\langle P^{2}\right\rangle}
$$

where $\Delta \mathrm{f}$ is the detection $\mathrm{BW}, \mathrm{S}_{\mathrm{P}}(\mathrm{f})$ is the spectral density of the power fluctuations, and $\langle\mathrm{P}\rangle$ is the mean $\mathrm{P}$. RIN will reduction with growing pumping rate. If the laser is worked in a multi-mode regime [36, 37]. Specifications of the blue laser and values of parameters can be seen in Table 1.

Table 1. Specifications of the Blue Laser and Values of Parameters

\begin{tabular}{cc}
\hline Parameters & Specifications \\
\hline Power & $100,250 \& 350 \mathrm{~mW}$ \\
$\lambda$ & $473 \mathrm{~nm}$ \\
Beam Size & $1.4 \pm 0.2 \mathrm{~mm}$ \\
Spacial Mode & TEM $_{00}$ \\
BW & $\leq 40 \mathrm{GHz}$ \\
Divergence & $<0.6 \mathrm{~m} \mathrm{rad}$ \\
Beam Angle & $1 \mathrm{~m} \mathrm{rad}$ \\
Operation Temp. & $15-35 \mathrm{C}^{0}$ \\
\hline
\end{tabular}

\section{CONCLUSIONS}

Blue laser could be advantageous for communication determinations and taking the buildup the advancing. Modules of blue laser can today be designed to fit a broad range of applications [38, 39].

Depending on the required output power, amplitude stability, reliability, frequency tunability, compactness and output wavelength, one can choose between a wide set of laser technology. This study contributes with several new laser setups which can potentially replace much more complex and expensive systems or even enable the realization of new applications. This was possible due to the development of novel laser schemes, mostly utilizing nonlinear optics. The influential beam of blue laser has developed a significant instrument for spectroscopic analysis.

A blue laser system is used for stimulating emission from solid models for spectrographic analysis. Additional quantities have been carried out utilizing like blue laser diodes for underwater data transmission and laser tracing. Researchers need enhanced approaches to accurately make new the blue laser applications to use modern experimental measurements.

\section{REFERENCES}

[1] Gerhard Fasol: "Longer life for the blue laser "SCIENCE, 278, pp.1902-1903, (12 Dec. 1997).

[2] Sylwester Porowski: "blue laser", Poland.gov.pl, (2010).

[3] V.Pruneri, R. Koch, P.G. Kazansky, W.A. Clarkson, P.St.J. Russell and D.C. Hanna Opt.Lett., vol. 20, pp. 2375-2377, (1995).

[4] Top GaN technology of blue/violet laser diodes.

[5] Arpad A. Bergh, "Blue laser diode (LD) and light emitting diode (LED) applications", phys.stat. sol. (a) 201, No. 12, 2740-2754 (2004).

[6] http://www.optique-ingenieur.org/en/courses /opi_ang_m05_c0.

[7] R. N. Hall, G. E. Fenner, J. D. Kingsley, T. J. Soltys and R. O. Carlsson, "Coherent Light emission from GaAs Junctions", Phys. Rev. Lett. 9, pp.366-368, (2012).

[8] "Solid State Electronic Devices", Prentice Hall New Jersey 7th edition, (2017).

[9] www.globalspec.com.

[10] N A M Ahmad Hambali, M Ajiya, M M Shahimin, M. H. A. Wahid, M A Mahdi," Single-wavelength ring-cavity fiber laser employed preamplification technique to reduce threshold by circulating spontaneous brillouin scattering", Indonesian Journal of Electrical Engineering and Computer Science, Vol. 14, No. 1, April (2019\}, pp. 276 283, ISSN: 2502-4752, DOI: 10.11591/ijeecs. V14.i1. pp276-283.

[11] Burhan Davarciogl, "An Overview of Diode Pumped Solid State (DPSS) Lasers", Aksaray University, Faculty of Science and Art, Department of Physics, 68100, Aksaray- TURKEY, (2016).

[12] Fan, T.Y. \& Byer, R.L., "Diode laser pumped solid state lasers", IEEE J. Quant. Electron, 24(6): pp. 895-912, (1988).

[13] Svelto, O. "Techniques of Solid-State Lasers "(Eds. Arrechi, F.T. and Dubois, S.E.O). Laser Handbook 1, NorthHolland, Amsterdam, pp.426-529, (1972).

[14] Dhanya S N1, Sherin Thomas 2,"Modeling, designing and structural analysis of GaN blue laser diode", AEI, Christ Knowledge City, Kerala, India IJRET (Mar.2014), Available @ http://www.ijret.org.

[15] Larry A Coldren, Scott W. Corzine, "Diode Lasers and Photonic", Wiley and Sons, Inc (2005). 
[16] Shuji Nakamura, Gerhard Fasol, Stephen J Pearton "the blue laser diode: The complete story " ISBN 2ed edition (Sept. 2000).

[17] R. Gunshot, A. Nurmikko, eds., "Semiconductors and Semimetals", Vol. 44, Academic Press, San Diego, (2007).

[18] S. Nakamura, T. Mukai, M. Senoh, "Candela-class high brightness InGaN/AlGaN double-heterostructure bluelight-emitting-diodes," Appl.Phys. Lett. 64, (2014).

[19] S. Nakamura and G. Fasol, "The Blue Laser Diode," Springer-Verlag Berlin Heidelberg New York, 2015.

[20] E.S. Polzik and H.J. Kimble, "Frequency doubling with Knob in an external cavity," Opt. 3 Lett., vol. 16, pp. 1400-1402, (2018).

[21] Strauß U., Brüninghoff S., Schillgalies M., Vierheiligc., Gmeinwieser N., Kümmler V., Brüderl G., Lutgen S., Avramescu A., Queren D., Dini D., Eichler C., Lell A., Schwarz U.T., "True-blue InGaN laser for Pico size projectors", Proceedings of SPIE 6894, (2008).

[22] E. Hooper, M. Kauer, V. Bousquet, K. Johnson, J. M. Barnes, and J. Heffernan, "InGaN multiple quantum well laser diodes grown by molecular beam epitaxy", Electron. Lett, vol. 40, pp. 33-34, (2014).

[23] S. Taniguchi, T. Hino, S. Itoh, K. Nakano, N. Nakayama, A. Ishibashi and M. Ikeda, "100hII-VI blue-green laserdiode," Electron, Lett., vol. 32, pp. 552-553, (1996).

[24] Heffernan, M. Kauer, S. E. Hooper, V. Bousquet, and K. Johnson, "In GaN violet laser diodes grown by molecular beam epitaxy", phys. stat. sol. (a), vol. 201, pp. 2688-2671, (2010).

[25] S. Nakamura, G. Fasol and Stephen J Pearton "The Blue Laser Diode the complete story ", (2013).

[26] Shuji Nakamura "The Roles of Structural Imperfections in InGaN-Based Blue Light-Emitting Diodes and Laser Diodes" Science Vol. 281 no. 5379 pp. 956-961,(2015).

[27] Yik-Khoon Ee, Pisist Kumnorkaew, "InGaN quantum wells light-emitting diodes with polydimethylsiloxane concave microstructures", Center for Optical Technologies, Department of Electrical and Computer Engineering, Lehigh University, Bethlehem, PA 18015, USA 2Center for Advanced Materials and Nanotechnology, Department Chemical Engineering, Lehigh University, Bethlehem, PA 18015, USA, (2012).

[28] K. McGroddy, A. David, E. Matioli, M. Iza, S. Nakamura, S. DenBaars, J. S. Speck, C. Weisbuch, and E. L. Hu, "Directional emission control and increased light extraction in GaN photonic crystal light emitting diodes," Appl. Lett. 93(10), 103502, (2008).

[29] A. Ishibashi, Y. Mori, "Advances in blue laser diode", J. of Crystal Growth Vol. 138, P.677-685, (Apr. 2011).

[30] Jihane Ouchrif, Abdennaceur Baghdad, Aicha Sshel, Abdelmajid Badri," Abdelhakim Ballouk, "Investigation of the static current gain for InP/InGaAs single heterojunction bipolar transistor", Indonesian Journal of Electrical Engineering and Computer Science (IJEECS), Vol 13, No 3: March (2019).

[31] Norliza Mohamed, Sevia Mahdaliza Idrus, Azura Hamzah, Suriani Mohd Sam, Norulhusna Ahmad, Hazilah Md Kaidi, Rudzidatul Akmam Dziyauddin, "All optical Millimeter-wave signal generation and transmission for radio over fiber (RoF) link", Indonesian Journal of Electrical Engineering and Computer Science (IJEECS), Vol 15, No 3: September( 2019).

[32] Nur Ameelia Abdul Kadir, Nurul Alina Afifi Norizan, Azura Hamzah "Pulse train stability in passively Modelocked Erbium-doped fiber laser with a nonlinear polarization rotation", Indonesian Journal of Electrical Engineering and Computer Science (IJEECS), Vol 15, No 3: September (2019), DOI: http://doi.org/10.11591/ijeecs.v15.i3.pp\%25p.

[33] Betten, John; Kollman, Robert; "LED Lighting Illuminates Buck Regulator Design", Power Electronics Technology, vol. 33, no. 10, pp. 38, (Oct. 2013).

[34] Lee, C., Zhang, C., Cantore, M., Farrell, R. M., Oh, S. H., Margalith, T., Speck, J. S., Nakamura, S., Bowers, J. E.and DenBaars, S. P., "4 Gbps direct modulation of $450 \mathrm{~nm}$ GaN laser for high-speed visible light communication" Optics Express 23(12), 16232-16237 (2015). https://doi.org/10.1364/OE.23.016232Google Scholar.

[35] Yamamoto, Y., ed., "Coherence. Amplification, and Quantum Effects in Semi- Conductor Lasers", Wiley Semiconductor Lasers, Artech House, Boston (1999).

[36] Arpad A. Bergh, "Blue laser diode (LD) and light emitting diode (LED) applications", phys. stat. sol. (a) 201, No. 12, 2740-2754 (2017).

[37] Wiley-VCH Verlag GmbH \& Co. KGaA, Weinheim, (2009), www.optik-photonik.de.

[38] Nakamura, S., Pearton, S. and Fasol, G., "The Blue Laser Diode", Springer (2017). https://doi.org/10.1007/978-3662-03462-0Google Scholar.

[39] Amir hossein Poursoltan mohammadi, M. chehel Amirani, Faghihi Faghihi," Comparison of Shielding Effectiveness in Complex Curved Structure with Different Numerical Methods, FDTD, MOM and Equivalent Circuit", Indonesian Journal of Electrical Engineering and Computer Science (IJEECS), Vol 12, No 3: December (2018). 